\title{
Platelet aggregation, eicosanoid production and thrombogenic ratio in individuals at high cardiovascular risk consuming meat enriched in walnut paste. A crossover, placebo-controlled study
}

\author{
Amaia Canales ${ }^{1}$, Sara Bastida ${ }^{1}$, Josana Librelottto ${ }^{1}$, Meritxell Nus ${ }^{1}$, Francisco J. Sánchez-Muniz ${ }^{1}$. \\ and Juana Benedi ${ }^{2}$ \\ ${ }^{1}$ Departamento de Nutrición y Bromatología I (Nutrición), Facultad de Farmacia, Universidad Complutense de Madrid, E-28040 \\ Madrid, Spain \\ ${ }^{2}$ Departamento de Farmacología, Facultad de Farmacia, Universidad Complutense de Madrid, E-28040 Madrid, Spain
}

(Received 26 June 2008 - Revised 16 October 2008 - Accepted 17 October 2008 - First published online 10 December 2008)

\begin{abstract}
Walnut consumption produces beneficial cardiovascular effects. The aim of the present study is to compare the effects of meat enriched in walnut paste $(\mathrm{WM})$ and low-fat meat (LM) consumptions on platelet aggregation, plasma thromboxane $\mathrm{A}_{2}\left(\mathrm{TXA}_{2}\right.$, measured as $\left.\mathrm{TXB}_{2}\right)$, prostacyclin $\mathrm{I}_{2}$ $\left(\mathrm{PGI}_{2}\right.$, as 6-keto- $\left.\mathrm{PGF}_{1 \alpha}\right)$ and the thrombogenic ratio $\left(\mathrm{TXB}_{2} / 6\right.$-keto- $\left.\mathrm{PGF}_{1 \alpha}\right)$ in volunteers at high CVD risk. Twenty-two adults were placed on a random, non-blinded crossover study involving two test periods (five portions WM/week for 5 week; five portions LM/week for 5 week) separated by a 4- to 6-week washout period. The participants were asked to complete a diet record throughout the study. Platelet aggregation, plasma $\mathrm{TXB}_{2}$, 6-keto- $\mathrm{PGF}_{1 \alpha}$ production and the $\mathrm{TXB}_{2} / 6-\mathrm{keto}-\mathrm{PGF}_{1} \alpha$ ratio were determined at baseline and at weeks 3 and 5 for the two dietary periods. The WM diet contains a lower SFA content, a higher concentration of PUFA and a more favourable $n-6 / n-3$ ratio than the LM diet. Significant time $\times$ treatment interactions were observed for $\mathrm{TXB}_{2}(P=0 \cdot 048)$ and the $\mathrm{TXB}_{2} / 6-$ keto- $\mathrm{PGF}_{1} \alpha$ ratio $(P=0 \cdot 028)$. The WM diet significantly increased the level of 6-keto- $\mathrm{PGF}_{1} \alpha(P=0.037)$ and decreased the $\mathrm{TXB}_{2} / 6$-keto-PGF ${ }_{1} \alpha$ ratio $(P=0.048)$. At week 5 , significant differences $(P<0 \cdot 05)$ between treatments were found for maximum aggregation rate, $\mathrm{TXB}_{2}$ values and the $\mathrm{TXB}_{2} / 6-\mathrm{keto}-\mathrm{PGF}_{1} \alpha$ ratio. The effects on $\mathrm{TXB}_{2}$ and the $\mathrm{TXB}_{2} / 6$-keto-PGF $1 \alpha$ ratio were time-course dependent $\left(P=0.019\right.$ and $0 \cdot 011$, respectively). The WM and LM diets reduced TXB $\mathrm{T}_{2}$ levels most

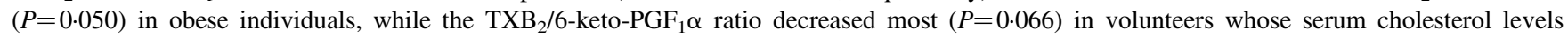
were $\geq 2200 \mathrm{mg} / \mathrm{l}$. The WM diet should be considered a functional meat because it improves the thrombogenic status mainly in individuals with high-cholesterol levels or high BMI.
\end{abstract}

Meat enriched in walnut paste: Low-fat meat: Platelet aggregation: Prostacyclin: Thromboxane: Thrombogenic ratio: Functional food

CHD are multifactorial disorders in which diet is known to play a major role. Dietary fatty acid composition may have an effect on the development of thrombosis and atherosclero$\operatorname{sis}^{(1,2)}$, although no conclusive agreement regarding this matter has yet been reached. In general terms, SFA may promote the formation of arterial thrombi, linoleic acid is antithrombotic, and oleic acid and other MUFA probably have little effect on arterial thrombosis ${ }^{(1)}$. Thus, Thijssen et al. ${ }^{(3)}$ reported that different authors found no effect of dietary SFA on platelet function, thromboxane (TX) generation or the excretion of $\mathrm{TXB}_{2}$ and prostacyclin $\mathrm{I}_{2}\left(\mathrm{PGI}_{2}\right.$, determined as 6-keto- $\left.\mathrm{PGF}_{1} \alpha\right)$. Sinclair ${ }^{(4)}$ postulated that a deficiency of arachidonic acid might lead to atherosclerosis; moreover, from a slightly different viewpoint, a diet high in SFA and low in essential fatty acids contributes to $\mathrm{CVD}^{(5)}$. Hornstra ${ }^{(6,7)}$ and Harris et al. ${ }^{(8)}$ indicate that a diet high in fish oils or $n-3$ fatty acids decreases platelet synthesis of the series-2 eicosanoids (e.g. $\mathrm{TXA}_{2}$ ). Moreover, both endothelial production of $\mathrm{PGI}_{2}$ and platelet synthesis of $\mathrm{TXA}_{2}$ decrease after consumption of $n-3$ fatty acids. However, in men, the effects of diets with a decreased linoleic/linolenic acid ratio differ from that of diets containing fish long-chain $n-3$ fatty acids because it further decreases $\mathrm{TXB}_{2}$ but increases the $\mathrm{PGI}_{2}$ productions ${ }^{(9)}$.

Previous studies by our research group suggest that culinary oil modifies platelet aggregation and thrombogenesis in postmenopausal women ${ }^{(10-12)}$. Moreover, hypercholesterolaemic subjects display increased platelet aggregation rate and thrombogenesis with respect to their normocholesterolaemic counterparts ${ }^{(10-13)}$.

$n$-3 Fatty acids, such as $\alpha$-linolenic, eicosapentaenoic and DHA, are considered important components of a balanced diet and are thought to be effective in preventing and treating $\mathrm{CVD}^{(14)}$. The nutrient and phytochemical composition of walnuts differentiates them from other nuts. Walnuts are rich in polyunsaturated $\alpha$-linoleic, $\alpha$-linolenic and $\gamma$-linolenic fatty acids, display a balanced $n-6 / n-3$ ratio $^{(15)}$ and contain the antioxidant tocopherol ${ }^{(15,16)}$ and other beneficial compounds, including proteins of high biological value (e.g. arginine), fibre, vitamins, tannins, folates and polyphenols ${ }^{(15,16)}$, all of which may provide additional antiatherogenic properties ${ }^{(17,18)}$.

Abbreviations: LM, low-fat meat; PGI, prostacyclin; TC, total cholesterol; TX, thromboxane; WM, walnut-enriched meat. 
Frequent intake of walnuts correlates inversely with myocardial infarction or mortality due to vascular ischaemic disease, regardless of other risk factors, such as age, overweight, hypertension, smoking and lack of exercise ${ }^{(19-22)}$. Due to their potential health benefits, increased walnut consumption has been recommended ${ }^{(20,24)}$. However, at present, walnut consumption remains relatively low in Spain $(2.65 \mathrm{~g} / \mathrm{d}$ in 2004) and other Mediterranean countries ${ }^{(25)}$. Consequently, several strategies, the most important of which has been the inclusion of walnuts in functional foods, have been adopted to increase their intake ${ }^{(26)}$.

Our research group has studied the effect of adding walnut paste, as a functional ingredient, to restructured meat and has found that consumption of this restructured meat significantly increases the concentration of certain endogenous antioxidants ${ }^{(27,28)}$. Moreover, a related study ${ }^{(29)}$ found that volunteers who consumed walnut-enriched meat displayed significantly lower LDL-cholesterol levels than those who ate low-fat meat (LM). Thus, it can be hypothesised that the intake of restructured beef steaks and sausages containing walnuts may also modify aggregation, $\mathrm{TXA}_{2}, \mathrm{PGI}_{2}$ and the thrombogenic ratio $\left(\mathrm{TXA}_{2} / \mathrm{PGI}_{2}\right)$ in individuals at increased $\mathrm{CHD}$ risk. The present study aims to compare the effects of meat enriched in walnut paste (WM) with those of LM on platelet aggregation, $\mathrm{TXB}_{2}$, 6-keto-protaglandin $\mathrm{F}_{1} \alpha$ (6-keto-PGF $\mathrm{F}_{1 \alpha}$ ) and the $\mathrm{TXB}_{2} / 6$-keto- $\mathrm{PGF}_{1 \alpha}$ ratio in volunteers consuming both meats. Moreover, because hypercholesterolaemia and obesity have been related to hyperaggregability and hypercoagulability $^{(30-32)}$, this study also analyses the effect of basal serum cholesterol levels and BMI on platelet aggregation and eicosanoid production in these volunteers.

\section{Subjects and methods}

\section{Subjects}

Twenty-five volunteers selected among the 144 candidates for the study were recruited through announcements in the media and hospitals. The volunteers had to fulfil the following eligibility criteria: (1) age, men $\geq 45$ years; women $\geq 50$ years and postmenopausal and (2) BMI $\geq 25$ to $<35 \mathrm{~kg} / \mathrm{m}^{2}$. The volunteers with a BMI $\geq 30 \mathrm{~kg} / \mathrm{m}^{2}$ were defined as obese. Moreover, at least one of the following criteria was also required: serum total cholesterol (TC) $\geq 5.69 \mathrm{mmol} / \mathrm{l}$; smoking habit $(\geq 10$ cigarettes per day) and/or hypertension (systolic pressure $\geq 140 \mathrm{mmHg}$ and/or diastolic pressure $\geq 90 \mathrm{mmHg}$ ). Exclusion criteria included familiar hypercholesterolaemia and/or type 1 diabetes, treatment with any lipid-lowering, antihypertensive or anti-inflammatory drugs and hormone replacement therapy.

Although many subjects were conscious of displaying three or more risk factors for CHD, some of them were not finally selected because they did not show a regular dietary habit of high meat consumption ( $\geq 5$ times/week). In addition, twenty-two volunteers were excluded for different reasons such as the habitual use of drug therapy. Three participants did not complete all the blood extractions and were excluded from the study. The characteristics of volunteers at the start of the dietary intervention are presented in Table 1.

Procedures followed were in accordance with the standards of the Ethics Committee of the University Hospital of Puerta
Table 1. Basal characteristics of participants at study entry (Mean values with their standard errors of twenty-two volunteers)

\begin{tabular}{|c|c|c|c|}
\hline Characteristic & Mean & SEM & Prevalence (\%) \\
\hline \multicolumn{4}{|l|}{ Sex } \\
\hline Males & & & 60 \\
\hline Females & & & 40 \\
\hline Age (years) & $54 \cdot 8$ & $2 \cdot 0$ & \\
\hline Weight (kg) & $81 \cdot 0$ & $2 \cdot 8$ & \\
\hline BMI $\left(\mathrm{kg} / \mathrm{m}^{2}\right)$ & $29 \cdot 6$ & 0.7 & \\
\hline $25-29.99 \mathrm{~kg} / \mathrm{m}^{2}$ & & & 60 \\
\hline$\geq 30 \mathrm{~kg} / \mathrm{m}^{2}$ & & & 40 \\
\hline \multicolumn{4}{|l|}{ Smokers } \\
\hline$\geq 10$ cigarettes $/ \mathrm{d}$ & & & 20 \\
\hline Systolic pressure $(\mathrm{mmHg})$ & $142 \cdot 0$ & $4 \cdot 7$ & \\
\hline$\geq 140 \mathrm{mmHg}$ & & & 64 \\
\hline Diastolic pressure $(\mathrm{mmHg})$ & $98 \cdot 3$ & 5.5 & \\
\hline$\geq 90 \mathrm{mmHg}$ & & & 72 \\
\hline Serum cholesterol $(\mathrm{mmol} / \mathrm{l})$ & $5 \cdot 64$ & 0.23 & \\
\hline$>5.65 \mathrm{mmol} / \mathrm{l}$ & & & 60 \\
\hline ATP III (10\% year estimated risk) & $12 \cdot 3$ & 0.9 & \\
\hline
\end{tabular}

ATP, Adult Treatment panel.

de Hierro (Madrid, Spain) and the Helsinki Declaration, as indicated in the guidelines of the Scientific Technologic Project AGL 2001-2398-C03. Volunteers provided informed consent previous to the start of the study.

\section{Study design}

Volunteers were randomly assigned to follow a non-blinded, crossover, placebo-controlled study, consisting of two 5-week experimental periods. The two periods were separated by a 4 to 6-week washout interval during which the subjects returned to their usual diet. During the WM period, the volunteers consumed four $150 \mathrm{~g}$ restructured WM steaks and a $150 \mathrm{~g}$ ration of WM sausages per week, all containing $20 \%$ WM. During the LM period, the volunteers consumed four $150 \mathrm{~g}$ restructured LM steaks and a $150 \mathrm{~g}$ ration of LM sausages each week. Table 2 shows the composition of the two types of meat. Further

Table 2. Energy content, proximate composition and some compound contents of meat enriched in walnut paste and low-fat meat*

\begin{tabular}{|c|c|c|}
\hline Characteristics & Low-fat meat† & $\begin{array}{l}\text { Meat enriched in } \\
\text { walnut paste }\end{array}$ \\
\hline Energy (kJ/100 g meat) & $403 \cdot 4$ & 873.6 \\
\hline Moisture ( $\mathrm{g} / 100 \mathrm{~g}$ meat) & $74 \cdot 7$ & $61 \cdot 1$ \\
\hline Protein (g/100 g meat) & $20 \cdot 6$ & $19 \cdot 5$ \\
\hline Fat ( $g / 100 \mathrm{~g}$ meat) & $1 \cdot 6$ & 14.5 \\
\hline Ash ( $\mathrm{g} / 100 \mathrm{~g}$ meat $)$ & $3 \cdot 1$ & $3 \cdot 2$ \\
\hline SFA (g/100 g total fatty acids) & $42 \cdot 1$ & $11 \cdot 2$ \\
\hline MUFA ( $\mathrm{g} / 100 \mathrm{~g}$ total fatty acids) & $38 \cdot 0$ & $13 \cdot 7$ \\
\hline PUFA ( $g / 100 \mathrm{~g}$ total fatty acids) & $19 \cdot 8$ & 74.9 \\
\hline$n-6 / n-3$ ratio & $10 \cdot 2$ & $3 \cdot 8$ \\
\hline Magnesium (mg/100 g meat) & $20 \cdot 2$ & $41 \cdot 4$ \\
\hline Lysine/arginine ratio & $1 \cdot 3$ & $1 \cdot 1$ \\
\hline$\alpha$-Tocopherol (mg/100 g meat) & $0 \cdot 1$ & 0.2 \\
\hline$\gamma$-Tocopherol (mg/100 g meat) & 0.01 & $4 \cdot 1$ \\
\hline$\delta$-Tocopherol (mg/100 g meat) & ND & 0.8 \\
\hline
\end{tabular}

ND, not detected.

${ }^{*}$ Adapted from Serrano et al. ${ }^{(26)}$.

$\dagger$ Restructured meat and sausages. 
information is available in Serrano et al. ${ }^{(26)}$. It was firmly recommended that all other meats and meat derivatives be excluded from the diet during the experimental periods.

\section{Dietary control and compliance}

The subjects received frozen LM and WM products once a week. Special emphasis was given to compliance and management of intake with regard to frequency, dates and numbers of steaks consumed. The volunteers completed a dietary record throughout the study in order to allow us to check compliance with the intervention and to confirm substitution of the meat products in their ordinary meals, while maintaining a mixed diet throughout the study periods. Dietary energy and nutrient intakes were calculated using food composition tables ${ }^{(33)}$. In order to avoid any possible dietary misunderstanding, volunteers recorded the amount and type of food consumed on a daily basis. Compliance was also assessed by measuring plasma $\gamma$-tocopherol concentrations after each experimental period $^{(34)}$. Most participants $(80 \%)$ enjoyed WM, although they considered this meat type to have a particular taste; however, a large percentage of volunteers (40\%) disliked the low palatability of LM.

\section{Anthropometric and blood pressure measurements}

Trained staff measured weight, height, BMI and systolic and diastolic blood pressures of the participants at the start and at weeks 3 and 5 of both dietary periods.

\section{Sample collection}

Overnight fasting blood samples were collected from all participants at baseline and at 3 and 5 weeks. During each visit to the hospital, the blood samples and dietary records of each participant were collected. In addition, blood pressure and body weight were recorded. Serum was separated by at $1500 \mathrm{~g}$ at $4^{\circ} \mathrm{C}$, for $30 \mathrm{~min}$ within $1 \mathrm{~h}$ of sampling. TC was determined in serum samples using a Technicon RA-500 autoanalyser (Tarrytown, NY, USA) and standard enzymatic procedures (Boehringer Mannheim, Mannheim, Germany). Commercially available quality controls (Precinorm reference 225053 and Precilip reference 781827; Boehringer Mannheim) were included in all assays.

Blood samples were mixed with $3.8 \%$ trisodium citrate (9:1 (v/v), blood/citrate). The anticoagulated blood was centrifuged at $200 \mathrm{~g}$ for $10 \mathrm{~min}$ to prepare platelet-rich plasma. Platelet counts on platelet-rich plasma samples were done in a haemocytometer, diluting platelet-rich plasma with saline solution. The number of platelets in platelet-rich plasma samples was adjusted with saline solution to $300000 / \mathrm{mm}^{3}$. Platelet aggregation was determined using ADP (Chromopag ADP, IZASA, Barclona, Spain) as the aggregating agent with an electronic aggregometer (model 500, Chronolog Corporation, IZASA-Coulter, Havertown, PA, USA), as reported by Cardinal \& Flower $^{(35)}$. Data were expressed as the maximum aggregation rate at $5 \mathrm{~min}(\mathrm{~cm} / 5 \mathrm{~min})$ and the time required for reaching the maximum aggregation rate $(\mathrm{min})$.

$\mathrm{TXB}_{2}$, a stable metabolite of $\mathrm{TXA}_{2}$, and 6-keto-PGF ${ }_{1 \alpha}$, a stable metabolite of $\mathrm{PGI}_{2}$, were extracted from citrated plasma samples using silica microcolumns (Chromabond ${ }^{\circledR}$ C18) coupled to a vacuum system (Manifold Vacuum Gauge Controller; J.T. Baker, Phillipsburg, NJ, USA) ${ }^{(36)}$. After extraction at $\mathrm{pH} 3$, an aliquot of the dry residue was reconstituted with the assay buffer for $\mathrm{TXB}_{2}$ determination $\left(\mathrm{TXB}_{2} / 2,3\right.$-Dinor$\mathrm{TXB}_{2}\left({ }^{125} \mathrm{I}\right)$ RIA kit Izotop, Budapest, Hungary) and another for the $\mathrm{PGI}_{2}$ analysis (6-keto-PGF $1 \alpha / 2,3$-dinor-6-keto-PGF $1 \alpha$ $\left({ }^{125} \mathrm{I}\right)$ RIA kit Izotop). The radioactivity of all tubes was measured using a Packard Mod Cobra auto-gamma counting system (Packard Instrument Company, Inc., Packard-Becker B.V.; BK Groningen, The Netherlands).

\section{Statistics}

Data are presented as means with their standard errors. Food and nutrient consumption was analysed by paired Student's $t$ test. The percentage change from the baseline $\mathrm{TXB}_{2}$ and $\mathrm{PGI}_{2}$ concentration was determined $a$ priori to be the primary outcome variables. The present study was designed to have a power of $80 \%$ to detect a $20 \%$ difference between the two meat-diet consumptions in the $\mathrm{TXB}_{2}$ and $\mathrm{PGI}_{2}$ response. A pooled SD of $30 \%$ for the change from baseline $\mathrm{TXB}_{2}$ and $\mathrm{PGI}_{2}$, based on previous studies ${ }^{(11,12,37)}$, was assumed for this calculation. The statistical power would be approximately $70 \%$, when compared with subgroups with nine to eleven participants classified according to BMI (higher or lower than $30 \mathrm{~kg} / \mathrm{m}^{2}$ ) or cholesterol levels (higher or lower than $2200 \mathrm{mg} / \mathrm{l})$.

Aggregation and eicosanoid changes were analysed by a two-factor (time and treatment) repeated-measures ANOVA. When there was a significant time $\times$ treatment interaction, the change over time within each group was assessed using a one-factor ANOVA, while a paired Student's $t$ test was used to compare differences at the same week between the two treatments. The inter-subject effects of TC and BMI were also tested. The linear adjustment between time of treatment and differences between the two periods was analysed by Pearson's product-moment correlations. Data were significant at $P<0.05$. The SPSS 15.0 statistical package was employed.

\section{Results}

Most of the important differences between WM and LM were in their fatty acid profiles. The WM diet displayed higher PUFA values and a lower $n-6 / n-3$ ratio than the LM diet (Table 2).

Food intake did not significantly differ throughout both the periods. SFA energy contribution was lower during the WM period, while PUFA $n-6$ and PUFA $n-3$ energy contributions and the $n-6 / n-3$ ratio were significantly higher (Table 3 ). Data on BMI, platelet aggregation, eicosanoid production and the thrombogenesis ratio at basal conditions and after weeks 3 and 5 of each period are presented in Table 4. BMI was not affected throughout the study. Non-significant time $\times$ treatment interaction $(P>0 \cdot 1)$ was found for maximum aggregation rate and the time for maximum aggregation. Maximum aggregation rate was significantly higher at week $5(P<0 \cdot 05)$ of the WM period than at the same week of the LM period. A significant time $\times$ treatment interaction was found for $\mathrm{TXB}_{2} \quad(P=0.048)$ and the $\mathrm{TXB}_{2} / 6$-keto-PGF ${ }_{1 \alpha}$ ratio $(P=0.025)$. $\mathrm{TXB}_{2}$ values were significantly lower at week 5 $(P<0.05)$ of the WM period than at the same week of the 
Table 3. Daily energy intake of macronutrients and fatty acid energy contribution during intervention and control periods (Mean values with their standard errors of twenty-two volunteers)

\begin{tabular}{|c|c|c|c|c|c|c|c|c|}
\hline & \multicolumn{2}{|c|}{ Low-fat meat period } & \multicolumn{2}{|c|}{$\begin{array}{l}\text { Meat enriched in wal- } \\
\text { nut paste period }\end{array}$} & \multicolumn{3}{|c|}{ Between-group comparison } & \multirow[b]{2}{*}{$P$} \\
\hline & Mean & SE & Mean & SE & Mean & SE & $95 \% \mathrm{Cl}$ & \\
\hline Energy (MJ) & 7419 & 1202 & 7721 & 1244 & $302 \cdot 0$ & $321 \cdot 1$ & $-366 \cdot 1,969 \cdot 9$ & 0.358 \\
\hline Carbohydrates (\%En) & 32.5 & 5.7 & $30 \cdot 1$ & 7.9 & -2.4 & 1.9 & $-6 \cdot 35,1.53$ & 0.217 \\
\hline Protein (\%En) & $19 \cdot 1$ & 0.7 & $18 \cdot 4$ & 0.7 & -0.70 & 0.94 & $-2 \cdot 66,1 \cdot 26$ & 0.467 \\
\hline Fat (\%En) & $45 \cdot 2$ & 1.6 & $46 \cdot 7$ & 1.5 & 1.5 & 0.94 & $-0.3,3.2$ & 0.185 \\
\hline SFA (\%En) & $16 \cdot 2$ & $1 \cdot 3$ & $12 \cdot 6$ & 0.6 & $-3 \cdot 6$ & $1 \cdot 2$ & $-6.09,-1.01$ & 0.008 \\
\hline MUFA (\%En) & $19 \cdot 9$ & $1 \cdot 3$ & $19 \cdot 2$ & $1 \cdot 0$ & -0.79 & 1.55 & $-4.01,2.44$ & 0.618 \\
\hline PUFA (\%En) & $7 \cdot 2$ & 0.7 & $13 \cdot 0$ & 0.6 & 5.9 & 0.9 & $4.06,7 \cdot 68$ & $<0.001$ \\
\hline Alcohol (g) & $3 \cdot 2$ & 1.4 & $4 \cdot 8$ & $2 \cdot 3$ & $1 \cdot 7$ & 2.9 & $-4 \cdot 36,7 \cdot 73$ & 0.568 \\
\hline$n 6$ PUFA (\%En) & 2.53 & $2 \cdot 37$ & $7 \cdot 92$ & 0.42 & $5 \cdot 4$ & 0.6 & $4 \cdot 18,6 \cdot 60$ & $<0.001$ \\
\hline n 3 PUFA (\%En) & 0.41 & 0.12 & 1.89 & 0.11 & 1.5 & 0.2 & $1 \cdot 16,1 \cdot 78$ & $<0.001$ \\
\hline$n 6$ PUFA/n 3 PUFA & $9 \cdot 78$ & 0.74 & $4 \cdot 23$ & 0.06 & $-5 \cdot 6$ & 0.7 & $-7.06,-4.04$ & $<0.001$ \\
\hline Linoleic acid/linolenic acid & 23.4 & $3 \cdot 0$ & $9 \cdot 9$ & 1.0 & $-10 \cdot 5$ & 1.4 & $-13 \cdot 5,-7 \cdot 5$ & 0.001 \\
\hline Cholesterol (mg) & $359 \cdot 8$ & $136 \cdot 1$ & $371 \cdot 2$ & $152 \cdot 1$ & 11.4 & $49 \cdot 4$ & $-91 \cdot 3,114 \cdot 2$ & 0.681 \\
\hline Fibre $(g)$ & $13 \cdot 4$ & $4 \cdot 7$ & $13 \cdot 4$ & $5 \cdot 8$ & 0.50 & 0.56 & $-2 \cdot 23,4 \cdot 86$ & 0.448 \\
\hline
\end{tabular}

$\%$ EN, percentage energy

LM period. 6-keto- $\mathrm{PGF}_{1 \alpha}$ increased $(P=0.037)$ throughout the WM period but no significant differences $(P>0 \cdot 1)$ were found between the two diets. The thrombogenic ratio decreased with the WM diet $(P=0.048)$ and was significantly lower $(P<0.05)$ at week 5 of the WM period than at the same week of the LM period (Table 4).

A significant correlation was found between the week of treatment and differences in $\mathrm{TXB}_{2}$ production between the two dietary periods, $Y=12.28-26.67 X(r$ 0.296; $P=0 \cdot 019)$, where $Y$ is the difference expected between $\mathrm{TXB}_{2}$ $\mathrm{WM}$ and $\mathrm{TXB}_{2} \mathrm{LM}$ values, and $X$ is the week of treatment.

Differences in the thrombogenic ratio between the two meat periods were significantly correlated with treatment week, $Y=0.290 ;-0.61 X(r 0.318 ; P=0.011)$, where $Y$ is the difference expected in the thrombotic ratio between the WM and LM periods, and $X$ the week of treatment.

No differences were observed throughout the treatments for maximum aggregation rate or time for maximum aggregation due to BMI or basal cholesterol levels. The effect of BMI and treatment on $\mathrm{TXB}_{2}$ levels and the thrombogenic ratio is shown in Fig. 1. $\mathrm{TXB}_{2}$ decreased most in obese individuals $(P=0 \cdot 050)$. The thrombogenic ratio of volunteers with the highest basal TC values who consumed WM tended to decrease more than those who consumed LM after week 5 $(P=0.066$; Fig. 2).

\section{Discussion}

To the best of our knowledge, this is the first study of the effect of WM on platelet aggregation and eicosanoid production. Moreover, no studies on the benefits of LM on these parameters have been carried out either.

BMI was not affected by WM diet consumption. These results are interesting, taking into account both the high-fat and energy contents of walnut ${ }^{(15)}$, and therefore their potential effect on body weight. Although no scientific papers on the effects of meat and/or walnut consumption on platelet aggregation, eicosanoid production and the thrombogenic ratio are available for a direct comparison of data, the results of studies on the effect of antioxidants, vitamins and PUFA on aggregation and thrombogenesis suggest that differences in some dietary compounds such as SFA, PUFA (total, $n-6$ and $n-3)$ and the $n-6 / n-3$ and linoleic acid/linolenic acid ratios between the two periods explain, at least partially, the variations between maximum aggregation values observed at week 5. The lower linoleic to linolenic acid ratio of the WM diet, together with other walnut compounds, must affect the platelet reaction capacity. In a previous study, platelet aggregation increased after ADP stimulation when oleic acid was substituted by palmitic acid ${ }^{(12)}$. According to Chan et al. ${ }^{(9)}$, oleic, linoleic and linolenic acids in platelet phospholipids reflect the fatty acid composition of the diet, although little linolenic acid is incorporated into phospholipids. Nonetheless, both $18: 3$ and the linoleic/linolenic ratio influenced the levels of longer-chain $n-3$ fatty acids, especially EPA, in platelet phospholipids.

The effect of treatment on time for maximum aggregation was more pronounced in individuals with serum cholesterol levels below $2200 \mathrm{mg} / \mathrm{l}$ (data not shown). Sanchez-Muniz et al. ${ }^{(12)}$ found significant differences in maximum aggregation between individuals with cholesterol levels above and below $2400 \mathrm{mg} / \mathrm{l}$ when a high-oleic acid diet was consumed, but reported that these differences were not significant with a palmolein diet. Sánchez-Muniz et al. ${ }^{(10)}$ also reported that substitution of extra virgin olive oil by high-oleic sunflower oil significantly increased the aggregation rate. Platelets of hypercholesterolaemics tended to aggregate earlier than those of normocholesterolaemics during the high-oleic acid sunflower oil period, although not in the virgin olive oil period.

Platelet aggregation is modulated by the production of $\mathrm{TXA}_{2}$ and $\mathrm{PGI}_{2}$. An optimal balance of $\mathrm{TXA}_{2} / \mathrm{PGI}_{2}$ may be important in the prevention of thrombotic conditions. Evidence indicates that dietary fatty acids can alter this balance ${ }^{(2,9)}$. Chan et al. ${ }^{(9)}$ found that $\mathrm{TXB}_{2}$ production in men significantly decreased when an oil mixture with a high-linoleic/linolenic ratio was substituted by an intermediate or low-linoleic/linolenic acid mixture. This effect was attributed to increased $20: 5 n-3$ fatty acid levels in platelet phospholipids. The WM diet contains a lower concentration of SFA and linoleic/linolenic and $n-6 \mathrm{PUFA} / n-3$ PUFA ratios that 

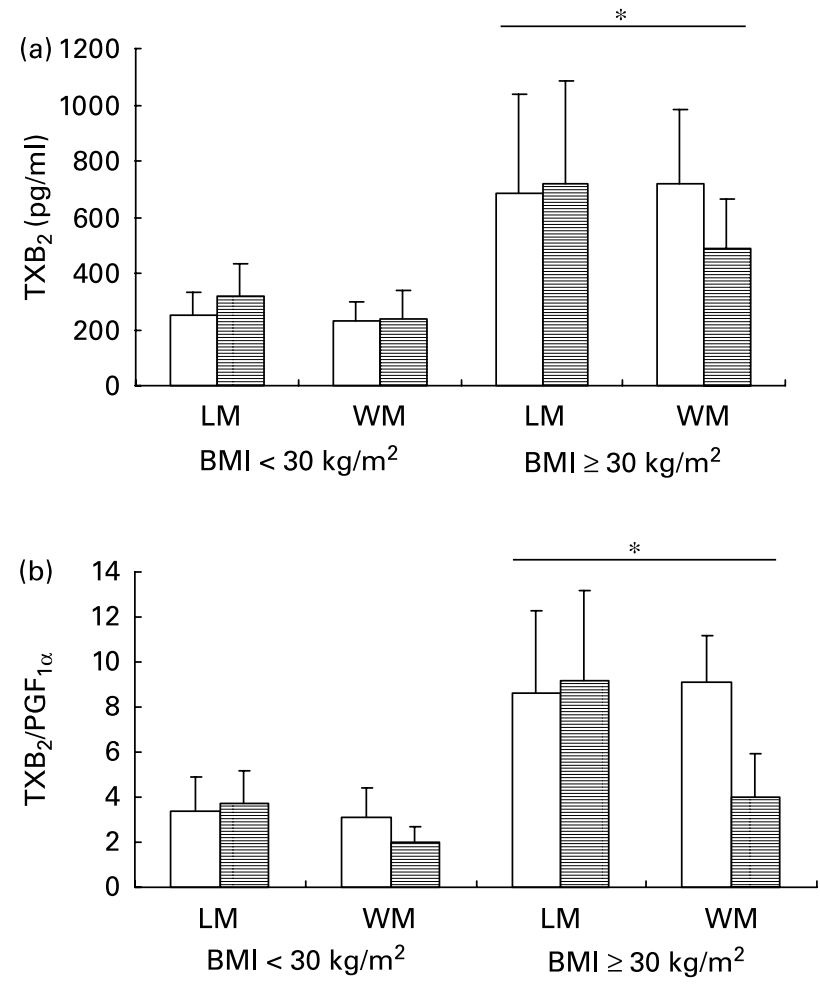

Fig. 1. Comparison of the effects of 5-week meat enriched in walnut paste (WM) $v$. low-fat meat (LM) consumption on changes in (a) thromboxane $\left(\mathrm{TXB}_{2}\right)$ values and $(\mathrm{b})$ the thrombogenic ratio $\left(\mathrm{TXB}_{2} / 6\right.$-keto-PGF $\left.{ }_{1 \alpha}\right)$ in overweight (BMl $<29.99 \mathrm{~kg} / \mathrm{m}^{2}, n$ 13) and obese (BMI $\geq 30 \mathrm{~kg} / \mathrm{m}^{2}, n$ 9) volunteers. Repeated measures followed by Bonferroni post hoc study (BMI effect: (a) $P=0.050$ and (b) $P=0.181$; meat effect: (a) $P=0.023$ and (b) $P=0.023$; $\mathrm{BMI} \times$ meat interaction: (a) $P=0.149$ and (b) $P=0.121$ ). Change (after 5 weeks minus basal) of bars indicated by a line and an asterisk was significantly different. Basal $(\square)$ and after 5 weeks (目).

are 2.5 times lower than those of the LM diet, explaining, at least partially, the present results.

Our group found that the substitution of extra virgin olive oil by oleic acid-rich sunflower oil increased in vitro platelet aggregation and $\mathrm{TXB}_{2}$ production ${ }^{(11)}$. These findings suggested that variations in the concentration of minor oil constituents may account for some of the differences observed in $\mathrm{TXB}_{2}$ levels after both dietary periods ${ }^{(11)}$. Proanthocyanidins, naturally occurring plant metabolites commonly found in fruits, vegetables, nuts, seeds, flowers and bark ${ }^{(38)}$, form part of a specific group of polyphenolic compounds called flavonoids ${ }^{(39)}$. These compounds are reported to have anti-inflammatory and vasodilatory properties ${ }^{(38,40)}$, to inhibit lipid peroxidation, platelet aggregation and capillary permeability and to affect, among others, the phospholipase $\mathrm{A}_{2}$, cyclo-oxygenase and lipoxygenase enzyme systems ${ }^{(38,40-42)}$.

One very interesting finding was the significant and negative adjustment between time of treatment and differences in $\mathrm{TXB}_{2}$ production between the two periods, suggesting, at least during the length of the study, that WM consumption partially inhibits, in a time-dependent manner, the $\mathrm{TXB}_{2}$ production.

Obesity has been related to hyperaggregability and thrombogenesis ${ }^{(30-32,43)}$. Obese individuals show $\mathrm{TXB}_{2}$ excretion three times higher than slim people ${ }^{(30)}$. In agreement with these findings, we observed that the overweight 

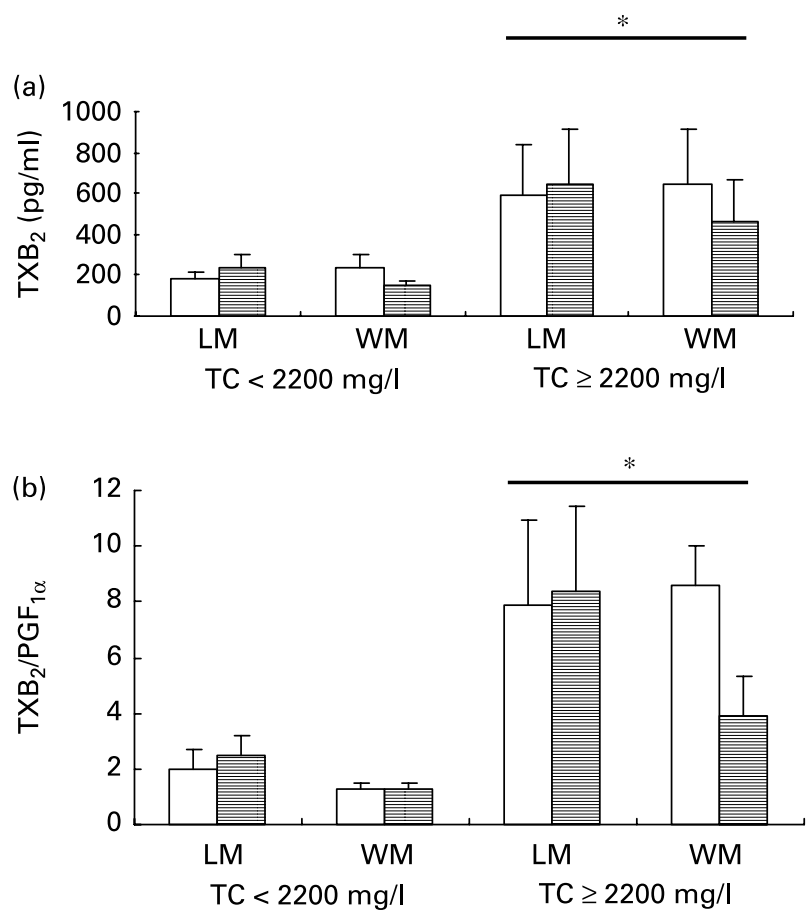

Fig. 2. Comparison of the effects of 5-week consumption of meat enriched in walnut paste (WM) $v$. low-fat meat (LM) on changes in (a) thromboxane $\left(\mathrm{TXB}_{2}\right)$ values and $(\mathrm{b})$ the thrombogenic ratios $\left(\mathrm{TXB}_{2} / 6\right.$-keto-PGF $\left.\mathrm{F}_{1 \alpha}\right)$ in low basal total cholesterol (TC) volunteers $(<2200 \mathrm{mg} / \mathrm{l}$ or $<5.64 \mathrm{mmol} / \mathrm{l}, n$ 9) and high basal TC volunteers ( $\geq 2200 \mathrm{mg} / \mathrm{l}, n$ 13). Repeated measures followed by Bonferroni post hoc study (cholesterol effect: (a) $P=0.200$ and (b) $P=0.066$; meat effect: (a) $P=0.079$ and (b) $P=0.035$; cholesterol $\times$ meat interaction: (a) $P=0.185$ and (b) $P=0.073$. Change (after 5 weeks minus basal) of bars indicated by a line and an asterisk was significantly different. Basal ( $\square$ ) and after 5 weeks (目).

individuals presented an average basal $\mathrm{TXB}_{2}$ concentration of approximately $240 \mathrm{pg} / \mathrm{ml}$, while their obese counterparts approximately $700 \mathrm{pg} / \mathrm{ml}$ (data not shown). Although WM consumption did not significantly change the body weight or $\mathrm{BMI}$ in the same volunteers ${ }^{(27)}$, it decreased $\mathrm{TXB}_{2}$ production by $20.2 \%$. This decrease was more relevant $(32.2 \%)$ in obese volunteers (data not shown), suggesting that obese individuals are the real target for WM consumption.

No clear differences between normocholesterolaemic and hypercholesterolaemic individuals were found with regard to the effect of the WM diet on $\mathrm{TXB}_{2}$ production, as levels decreased by approximately $40 \%$ in both cholesterol groups. Oubiña et al. ${ }^{(11)}$ reported that the dietary exchange of olive oil by high-oleic acid sunflower oil had a similar effect on $\mathrm{TXB}_{2}$ production in subjects whose cholesterol levels were above and below $6.21 \mathrm{mmol} / \mathrm{l}$.

In agreement with Chan et al. ${ }^{(9)}$, the decrease in the dietary linoleic/linolenic ratio increased by $30 \%$ 6-keto-PGF ${ }_{1 \alpha}$ levels. Animals consuming a diet containing more than $4 \%$ linoleic acid displayed lower or identical aortic $\mathrm{PGI}_{2}$ synthesis than those whose diet included less than $4 \%$ linoleic acid ${ }^{(44)}$. Low concentrations of linoleic acid decreased in vitro cyclooxygenase production by human platelets and thus the synthesis of both $\mathrm{TXB}_{2}$ and $\mathrm{PGI}_{2}$. At high concentrations, however, linoleic acid decreased cyclo-oxygenase and TX synthase activities, while $\mathrm{PGI}_{2}$ synthesis increased ${ }^{(44)}$. Oubiña et al. ${ }^{(11)}$ reported that BMI and cholesterol levels did not significantly influence the effect of diet on prostacyclin production, and Sánchez-Muniz et al. ${ }^{(12)}$ also found that serum cholesterol levels had no significant effect on the modulation of eicosanoid production by the dietary exchange.

WM positively affected the thrombogenic ratio of volunteers. The differences between the thrombogenic ratios of both dietary periods increased over time. This finding suggests that WM has a strong effect on thrombogenesis. As previously commented, Chan et al. ${ }^{(9)}$ found that the thrombogenic ratio in men significantly improved when an oil mixture with a high-linoleic/linolenic ratio was substituted by an intermediate or low-linoleic/linolenic acid. Several walnut compounds may be involved. Thus, it has been suggested that tocopherol may decrease thrombogenesis ${ }^{(42,45)}$. Furthermore, polyphenols, which are present in walnuts and some vegetables as condensed tannins, may decrease platelet aggregation and the enzymes that participate in eicosanoid production ${ }^{(41,42,46)}$.

The positive effect of WM on the thrombogenic ratio was relevant in the hypercholesterolaemic volunteers. By contrast, Oubiña et al. ${ }^{(11)}$ and Sánchez-Muniz et al. ${ }^{(12)}$ found that the serum cholesterol level did not modify the effect of diet on the thrombogenic ratio.

In conclusion, the effects on $\mathrm{TXB}_{2}$ and the thrombogenic ratio suggest that consumption of WM helps to decrease thrombogenic risk. Moreover, the results suggest that dietary treatment, more than BMI or basal TC, affected the thrombogenic ratio at week 5. Obese and hypercholesterolaemic individuals were more sensitive to the effect of WM. More studies are needed to better understand the physiological effect of changes induced by the consumption of meat enriched in $\mathrm{WM}$, and to assess the role of some minor walnut compounds over a longer period of time.

\section{Acknowledgements}

Funds for this study were granted by the Spanish Ministerio de Educación y Ciencia, Project AGL 2001-2398-C03 and AGL 2005-07 204-C02-01/ALI and Consolider-Ingenio 2010, reference CSD2007-00 016. We are grateful for the valuable assistance in TX and prostacyclin determination given by the Department of Physiology of the Medical School of the Universidad Complutense of Madrid. Thanks are due to the Universidad Complutense of Madrid for the predoctoral fellowship of M. N. All authors have significantly contributed to the paper and agree with the present version of the manuscript. F. J. S.-M. has contributed to the study design, volunteers' selection, data discussion and writing of the paper. J. B., S. B. and A. C. have contributed to the data acquisition and analysis and writing of the paper, M. N. and J. L. have contributed to the volunteers' selection, data analysis and writing of the paper. The work has been performed according to the ethical bases of the Helsinki Declaration. Volunteers provided informed consent previous to the start of the study. The authors declare that there are no conflicts of interest.

\section{References}

1. Knapp HR (1997) Dietary fatty acids in human thrombosis and haemostasis. Am J Clin Nutr 65, 1687S-1698S. 
2. Kwon JS, Snook JT, Wardlow GM, et al. (1991) Effects of diets high in saturated fatty acids, canola oil, or safflower oil on platelet function, thromboxane $\mathrm{B}_{2}$ formation, and fatty acid composition of platelet phospholipids. Am J Clin Nutr 54, 341-348.

3. Thijssen MA, Hornstra G \& Mensink RP (2005) Stearic, oleic, and linoleic acids have comparable effects on markers of thrombotic tendency in healthy human subjects. J Nutr 135, 2805-2811.

4. Sinclair HM (1956) Deficiency of essential fatty acids and atherosclerosis, etcetera. Lancet 270, 381-383.

5. Lee J \& Hwang DH (2007) Dietary fatty acids and eicosanoids In Fatty Acids in Foods and Their Implications, 3rd ed., pp. 715-726. Boca Raton, FL: CRC Press.

6. Hornstra G (1989) Effect of dietary lipids on platelet function and thrombosis. Ann Med 21, 53-57.

7. Hornstra G (1989) Dietary lipids, platelet function and arterial thrombosis. Wien Klin Wochenschr 101, 272-277.

8. Harris WS, Miller M, Tighe AP, et al. (2008) Omega-3 fatty acids and coronary heart disease risk: clinical and mechanistic perspectives. Atherosclerosis 197, 12-24.

9. Chan JK, McDonald BE, Gerrard JM, et al. (1993) Effect of dietary alpha-linolenic acid and its ratio to linoleic acid on platelet and plasma fatty acids and thrombogenesis. Lipids $\mathbf{2 8}$, $811-817$

10. Sánchez-Muniz FJ, Oubiña P, Benedí J, et al. (1998) Preliminary study platelet aggregation in postmenopausal women consuming extra virgin olive oil and high oleic acid sunflower oil. J Am Oil Chem Soc 75, 217-223.

11. Oubiña P, Sanchez-Muniz FJ, Ródenas S, et al. (2001) Eicosanoid production, thrombogenic ratio, and serum and LDL-peroxides in normo and hypercholesterolaemic post-menopausal women consuming two oleic acid-rich diets with different content of minor components. Br J Nutr 85, 41-47.

12. Sánchez-Muniz FJ, Oubiña P, Ródenas S, et al. (2003) Platelet aggregation, thromboxane production and thrombogenic ratio in postmenopausal women consuming high oleic acid-sunflower oil or palmolein. Eur J Nutr 42, 299-306.

13. Miller GJ (1993) Hyperlipidaemia and hypercoagulability. Prog Lipid Res 32, 61-69.

14. Gebauer SK, Psota TL \& Harris WS (2006) n-3 fatty acid dietary recommendations and food sources to achieve essentiality and cardiovascular benefits. Am J Clin Nutr 83, 6 Suppl., $1526 \mathrm{~S}-1535 \mathrm{~S}$

15. Nus M, Ruperto M \& Sánchez-Muniz FJ (2004) Nuts, cardio and cerebrovascular risks. A Spanish perspective. Arch Latinoam Nutr 54, 137-148.

16. Tapsell LC, Gillen LJ, Patch CS, et al. (2004) Including walnuts in a low-fat/modified-fat diet improves HDL cholesterol-to-total cholesterol ratios in patients with type 2 diabetes. Diabetes Care 27, 2777-2783.

17. Anderson KJ, Teuber SS, Gobeille A, et al. (2001) Walnut polyphenolics inhibit in vitro human plasma and LDL oxidation. J Nutr 13, 2837-2842.

18. Almario RU, Vonghavaravat V, Wong R, et al. (2001) Effects of walnut consumption on plasma fatty acids and lipoproteins in combined hyperlipidemia. Am J Clin Nutr 74, 72-79.

19. Iwamoto M, Imaizumi K, Sato M, et al. (2002) Serum lipid profiles in Japanese women and men during consumption of walnuts. Eur J Clin Nutr 56, 629-637.

20. Feldman EB (2002) The scientific evidence for a beneficial health relationship between walnuts and coronary heart disease. J Nutr 132, S1062-S1101.

21. Ros E, Nunez I, Pérez-Heras A, et al. (2004) A walnut diet improves endothelial function in hypercholesterolemic subjects: a randomized crossover trial. Circulation 109, 1609-1614.

22. Sabate J (1999) Nut consumption, vegetarian diets, ischemic heart disease risk, and all-cause mortality: evidence from epidemiologic studies. Am J Clin Nutr 70, 500S-503S.
23. US Food and Drug Administration Office of Nutritional Products, Labelling and Dietary Supplements (2004) Qualified Health Claims: Letter of Enforcement Discretion - Walnuts and Coronary Heart Disease. http://www.cfsan.fda.gov/ dms/ qhenuts3.html (accessed 28 October 2004).

24. National Heart, Lung and Blood Institute (2004) ATP 3 Cholesterol Guidelines. http://www.nhlbi.nih.gov/guidelines/cholesterol (accessed 28 October 2005).

25. Aranceta Bartrina J, Pérez Rodrigo C, Ruiz Vadillo V, et al. (2005) Consumo de frutos secos en España y en Europa. In Frutos secos, salud y culturas Mediterráneas, pp. 77-96 [J Salas-Salvadó, E Ros Róala and J Sabaté Casellas, editors]. Barcelona: Glosa

26. Serrano A, Cofrades S, Ruiz-Capillas C, et al. (2005) Nutritional profile of restructured beef steak with added walnuts. Meat Sci 70, 647-654.

27. Canales A, Benedí J, Nus M, et al. (2007) Effect of walnutenriched restructured meat in the antioxidant status of overweight/obese senior subjects with at least one extra CHD-risk factor. J Am Coll Nutr 26, 225-232.

28. Nus M, Frances F, Librelotto J, et al. (2007) Arylesterase activity and antioxidant status depend on PON1-Q192R and PON1-L55M polymorphisms in subjects with increased risk of cardiovascular disease consuming walnut-enriched meat. J Nutr 137, 1783-1788.

29. Olmedilla-Alonso B, Granado-Lorencio F, Herrero-Barbudo C, et al. (2008) Comsumption of restructured meat products with added walnuts has a cholesterol-lowering effect in subjects at high cardiovascular risk: a randomised, crossover, placebo-controlled study. J Am Coll Nutr 27, 342-348.

30. Basili S, Pacini G, Guagnano MT, et al. (2006) Insulin resistance as a determinant of platelet activation in obese women. J Am Coll Cardiol 48, 2531-2538.

31. Coban E, Yilmaz A \& Sari R (2007) The effect of weight loss on the mean platelet volume in obese patients. Platelets 18, 212-216.

32. Vignini A, Nanetti L, Moroni C, et al. (2008) Platelet nitric oxide production and IR: relation with obesity and hypertriglyceridemia. Nutr Metab Cardiovasc Dis 18, 553-558.

33. Moreiras O, Carbajal A \& Cabrera L (editors) (2007) Tablas de Composición de Alimentos. Madrid: Editorial Pirámide.

34. Olmedilla Alonso B, Granado Lorencio F, Herrero Barbudo C, et al. (2005) Productos cárnicos funcionales preparados con nuez. Evaluación del efecto funcional. Alimentación 24, 37-41.

35. Cardinal DC \& Flower RJ (1980) The electronic aggregometer: a novel device for assessing platelet behavior in blood. J Pharmacol Methods 3, 135-158.

36. Hishinuma T, Yu GS, Takabatake M, et al. (1996) Analysis of the thromboxane/prostacyclin balance in human urine by gas chromatography/selected ion monitoring: abnormalities in diabetics. Prostaglandins Leukot Essent Fatty Acids 54, 445-449.

37. Mensink RP, van Houwelingen AC, Kromhout D, et al. (1999) A vitamin $\mathrm{E}$ concentrate rich in tocotrienols had not effect on serum lipids, lipoproteins, or platelet function in men with mildly elevated serum lipid concentrations. Am J Clin Nutr 69, 213-219.

38. Bagchi D, Garg A, Krohn RL, et al. (1997) Oxygen free radical scavenging abilities of vitamin $\mathrm{C}$ and $\mathrm{E}$, and a grape seed proanthocyanidin extract in vitro. Res Commun Mol Pathol Pharmacol 95, 179-189.

39. Bravo L (1998) Polyphenols: chemistry, dietary sources, metabolism, and nutritional significance. Nutr Rev 56, 317-333.

40. Bagchi D, Garg A, Krohn RL, et al. (1998) Protective effect of grape proanthocyanidins and selected antioxidants against TPA-induced hepatic and brain lipid peroxidation and DNA fragmentation, and peritoneal macrophage activation in mice. Gen Pharmacol 30, 771-776. 
41. Murray M \& Pizzorno J (1999) Procyanidolic oligomeriers. In The Textbook of Natural Medicine, 2nd ed., pp. 899-902 [M Murray and J Pizzorno, editors]. London: Churchill Livington.

42. Robert L, Godeau G, Gavignet-Jeannin C, et al. (1990) The effect of procyanidolic oligomers on vascular permeability. A study using quantitative morphology. Pathol Biol (Paris) 38, 608-616.

43. Anfossi G, Russo I, Massucco P, et al. (2004) Impaired synthesis and action of antiaggregating cyclic nucleotides in platelets from obese subjects: possible role in platelet hyperactivation in obesity. Eur J Clin Invest 34, 482-489.
44. Srivastava KC (1985) Docosahexaenoic acid (C22:6 omega 3) and linoleic acid are anti-aggregatory, and alter arachidonic acid metabolism in human platelets. Prostaglandins Leukot Med 7, 319-327.

45. Szczeklik A, Gryglewski RJ, Domagala B, et al. (1985) Dietary supplementation with vitamin $\mathrm{E}$ in hyperlipoproteinemias: effects on plasma lipid peroxides, antioxidant activity, prostacyclin generation and platelet aggregability. Thromb Haemost 54, 425-430.

46. Fine AM (2000) Oligomeric proanthocyanidin complexes: History, structure, and phytopharmaceutical applications. Alternative Med Rev 5, 144-151. 